\title{
Global change induced trends in ion composition of the troposphere to the lower thermosphere
}

\author{
G. Beig \\ Indian Institute of tropical Meteorology, Pashan, Pune-411008, India \\ Received: 10 May 2007 - Revised: 27 June 2007 - Accepted: 28 June 2007 - Published: 28 May 2008
}

\begin{abstract}
In this paper a brief overview of the changes in atmospheric ion compositions driven by the human-induced changes in related neutral species, and temperature from the troposphere to lower thermosphere has been made. It is found that ionic compositions undergo significant variations. The variations calculated for the double- $\mathrm{CO}_{2}$ scenario are both long-term and permanent in nature. Major neutrals which take part in the lower and middle atmospheric ion chemical schemes and undergo significant changes due to anthropogenic activities are: $\mathrm{O}, \mathrm{O}_{2}, \mathrm{H}_{2} \mathrm{O}, \mathrm{NO}$, acetonitrile, pyridinated compounds, acetone and aerosol. The concentration of positive ion/electron density does not change appreciably in the middle atmosphere but indicates a marginal decrease above about $75 \mathrm{~km}$ until about $85 \mathrm{~km}$, above which the magnitude of negative trend decreases and becomes negligible at $93 \mathrm{~km}$. Acetonitrile cluster ions in the upper stratosphere are likely to increase, whereas $\mathrm{NO}^{+}$and $\mathrm{NO}^{+}\left(\mathrm{H}_{2} \mathrm{O}\right)$ in the mesosphere and lower thermosphere (MLT) region are expected to decrease for the double $\mathrm{CO}_{2}$ scenario. It is also found that the atmospheric density of pyridinated cluster ions is fast rising in the troposphere.
\end{abstract}

Keywords. Atmospheric composition and structure (Ion chemistry of the atmosphere) - Ionosphere (Ion chemistry and composition) - Atmospheric composition and structure (Middle atmosphere - composition and chemistry)

\section{Introduction}

At the present time, there is a great deal of interest placed on anthropogenically-induced perturbations in the atmosphere and their impact on global climate change. It has recently been realized that such influences are not only confined to the lower atmosphere but may also affect the middle and up-

Correspondence to: G. Beig

(beig@tropmet.res.in) per atmosphere (Beig, 2006; Beig et al., 2003; Roble and Dickinson, 1989). However, until recently, it was not known whether these changes also impact on the ion composition of the atmosphere. This question was addressed in detail by Beig and Mitra (1997b) for the middle atmosphere and by Thomas (1996) for the ionosphere. In fact, Beig and Brasseur (1999) postulated that human activities might influence the tropospheric ion composition, as well. Danilov (1997) and Danilov and Smirnova (1997) have reviewed the long-term variations in temperature and composition of the mesosphere and thermosphere. Roble and Dickinson (1989) and Rishbeth and Roble (1992) were the first to initiate the studies that related possible changes in the ionospheric structure to increasing concentrations of greenhouse gases from anthropogenic activities. Rishbeth (1997) reported that changes in ionospheric parameters, such as the lowering of the $F_{2}$ layer peak height, are due to changing boundary conditions in the mesopause region. Beig and Mitra (1997a, b) have recently examined a potentially important role of changes in the atmospheric neutral constituents and thermal structure on the distribution of stratospheric and mesospheric ionization and reported a significant variation in several ionic parameters. Recently, Chakrabarty (2005) has reported an increase in electron density at the $80-\mathrm{km}$ altitude as a result of negligible trends in temperature of the mesopause region.

A major driving factor in perturbing the ion composition in all the layers of the atmosphere is temperature, which may act through reaction rates of production and loss mechanisms. In addition, there are several neutral trace gases, which take part in the ion chemistry. If they undergo some changes, then they are likely to affect the ionic species. The review of systematic changes in temperature trend in the stratosphere and mesosphere has been given by Ramaswamy et al. (2001) and Beig et al. (2003), respectively. Thereafter, the quantification of temperature perturbations in ion chemical schemes can be appropriately taken into account. In this work, we briefly summarize ion chemical schemes

Published by Copernicus Publications on behalf of the European Geosciences Union. 
valid in different layers of the atmosphere, namely the troposphere, stratosphere and mesosphere. However, the major aim of this paper is to discuss the long-term anthropogenic impact on ion composition in these 3 different layers of the atmosphere, which is governed by 3 different ion chemical schemes. Results obtained by a double $\mathrm{CO}_{2}$ scenario are summarized for the stratosphere and mesosphere while for the troposphere we discuss the perturbations caused due to variations of related neutrals, which are assumed to vary by some factor along with temperature perturbation.

\section{Mesospheric and Lower Thermospheric ion chemical scheme}

The details of the positive ion chemical scheme used in the present study are given elsewhere (Beig, 2000; Chakrabarty et al., 1978). In the MLT region, there are mainly 3 families of ions, namely water cluster ions; $\mathrm{O}_{2}^{+}$and its water cluster ions; $\mathrm{NO}^{+}$and its water cluster ions. The $\mathrm{O}^{+}, \mathrm{O}_{4}^{+}$ and $\mathrm{O}_{2}{ }^{+}\left(\mathrm{H}_{2} \mathrm{O}\right)$ are the major positive ions in the $\mathrm{O}_{2}^{+}$family of ions. The water cluster ions involves $\mathrm{H}^{+}\left(\mathrm{H}_{2} \mathrm{O}\right)_{n}$, where " $n$ " may be $1,2,3, \ldots$ The sum of all the water cluster ions of this family is represented as PH ions in the discussion. The 3rd family of ions in the MLT region consists of $\mathrm{NO}^{+}, \mathrm{NO}^{+}\left(\mathrm{H}_{2} \mathrm{O}\right), \mathrm{NO}^{+}\left(\mathrm{H}_{2} \mathrm{O}\right)$ n, where "n" can be 1,2 , $3, \ldots$.Subsequently other minor ions are also formed (viz. $\mathrm{NO}^{+} \mathrm{H}_{2} \mathrm{O} \mathrm{CO}{ }_{2}, \mathrm{NO}^{+} \mathrm{CO}_{2}$, etc.) but their concentrations are negligible, as compared to the above mentioned 3 families. Several of the reaction rates used in this scheme have recently been updated and they are found to be temperature dependant, which may play a major role when perturbation studies are performed (Beig, 2000). The MLT scheme is used for the altitude range from $60-110 \mathrm{~km}$. The sources of production of ionization in the MLT region are well known. The primary ionization production processes are: (1) for height above $80 \mathrm{~km}$, the ionization of the major constituents is by $\mathrm{X}$-rays of wavelength less than $100 \AA$ and (ii) for height below $65 \mathrm{~km}$, the ionization of major constituents is by galactic cosmic rays and (iii) in the intermediate height range, solar Lyman-alpha ionizes minor constituents NO. The solar Lyman-alpha penetrates into the D-region through one of the narrow windows of the atmosphere. There are other processes involved, like ionization of $\mathrm{O}_{2}\left({ }^{1} \Delta \mathrm{g}\right)$ in the wavelength range of $1118 \AA$ to $1025 \AA$. The loss of ions in the MLT region is mostly by recombination of the positive ions with negative ions and with electrons. In the present study, the ion-ion recombination is taken as $6 \times 10^{-8} \mathrm{~cm}^{3} \mathrm{~s}^{-1}$. The dissociation recombination coefficient is different for different positive ions. In the present case, their values are those used by Beig and Mitra (1997b).

\section{Stratospheric ion chemical scheme}

The production mechanism of stratospheric ions starts with the ionization of $\mathrm{O}_{2}$ and $\mathrm{N}_{2}$ by galactic cosmic rays to form the precursor positive ions $\mathrm{O}_{2}^{+}$and $\mathrm{N}_{2}^{+} \cdot \mathrm{N}_{2}^{+}$immediately converts to $\mathrm{O}_{2}^{+}$by charge exchange with $\mathrm{O}_{2}$. In the following chain of reactions, water cluster ions are formed of the type $\mathrm{H}^{+}\left(\mathrm{H}_{2} \mathrm{O}\right)_{n}$, representing the sum of all major water cluster ions, known as proton hydrate $(\mathrm{PH})$ ions, where $\mathrm{n}=1,2,3, \ldots$ When these water cluster ions react with acetonitrile $\left(\mathrm{CH}_{3} \mathrm{CN}\right)$, acetonitrile water cluster ions, of the type $\mathrm{H}^{+} \mathrm{CH}_{3} \mathrm{CN}\left(\mathrm{H}_{2} \mathrm{O}\right)_{m}$, are formed, where $\mathrm{m}=1,2,3, \ldots$ This later family is known as non-proton hydrate (NPH) ion. In the presence of small-sized aerosol particles, the process of aerosol attachment with acetonitrile water cluster ions takes place and complex heavy aerosol cluster ions are formed which are represented as $\mathrm{H}^{+}$(aerosol) $\mathrm{CH}_{3} \mathrm{CN}\left(\mathrm{H}_{2} \mathrm{O}\right)_{m}$. The loss of ions in the stratosphere is mainly due to ion-ion recombination and attachment processes. The value of ion-ion recombination is given by Beig et al. (1993) for both twobody and three-body recombination coefficients and that of effective attachment coefficient $\left(\beta=2 \times 10^{-6} \mathrm{~cm}^{3} / \mathrm{s}\right)$ is mentioned by Beig and Brasseur (1999).

\section{Perturbation scenario and model experiments}

The temperature and all the neutrals which can be used in the ion chemical scheme are normally taken from a 2-D model. In the present case, the 2-D model which calculates these parameters includes 64 neutral species of the oxygen, hydrogen, nitrogen, chlorine, fluorine, bromine, carbon, and sulfur families and extends from 15 to $120 \mathrm{~km}$. The detail of the model is given elsewhere (Beig, 2000). Curtis and Goody (1956) found a breakdown of local thermal equilibrium (LTE) in the middle atmosphere for the $15-\mu \mathrm{m} \mathrm{CO}$ band above about $70 \mathrm{~km}$. Hence, we adopted the non-LTE approach in the spectral region of $\mathrm{CO}_{2}$ (Berger and Dameris, 1993; Akmaev and Fomichev, 1998) in the model. For the region between 15 and $60 \mathrm{~km}$, the Newtonian cooling approximation is used because non-LTE is not likely to exist at those altitudes. The 2-D model first calculates the concentrations of neutral species which are used as input to the stratospheric and mesospheric ion chemistry. Continuity equations for all ions in a particular scheme are written and solved simultaneously for steady-state conditions, assuming ionic charge neutrality. Calculations are performed at an interval of $1 \mathrm{~km}$ and from pole to pole with a $5^{\circ}$ resolution. The forcing parameters, which will most likely undergo a drastic change with time, due to human activities, are carbon dioxide, nitrous oxide, methane, and chlorofluorocarbons (CFCs). This is anticipated based on the present growth rates of these greenhouse gases (WMO, 1999). These trace gases contribute the most to changes in the chemical and thermal structure of the atmosphere. In the present work the prediction of future 
climate responses in the stratosphere is examined as semicontinuous time lines of quantities, such as chlorine loading and other trace gas variations, well into the 21 st century. We assumed that the tropospheric volume mixing ratio of carbon dioxide by the end of 2050 would be twice that of the present-day value (1995 reference level), and it is taken as $712 \mathrm{ppm}$. The methane mixing ratio is also considered to be doubled $(3.4 \mathrm{ppm})$ relative to 1995 . Nitrous oxide and CFCs are taken as per the business-as-usual scenario (BAU) (Beig and Mitra, 1997a) and yield an $\mathrm{N}_{2} \mathrm{O}$ volume mixing ratio of $365 \mathrm{ppb}$ and total chlorine loading, due to the CFCs of $11.7 \mathrm{ppb}$. Concentrations of all other species, including $\mathrm{SO}_{\mathrm{x}}$, are kept at ambient levels, with the assumption that they may not play a significant role in our model calculations. The above mentioned scenario will be referred as the "double- $\mathrm{CO}_{2}$ case" and the variation in different parameters for this scenario is calculated with respect to reference level (1995) in this paper. To filter out an effect due to changes in the solar activity, we assume identical solar activity conditions for 1995 and in the double- $\mathrm{CO}_{2}$ case. Major neutrals which take part in MLT ion chemical schemes and are likely to induce the variations in ion compositions are: $\mathrm{O}, \mathrm{O}_{2}, \mathrm{H}_{2} \mathrm{O}$, and NO. In addition to these neutrals, acetonitrile and aerosol also become important for the stratospheric region, whereas NO is important mainly for the MLT region ion chemistry. The vertical distribution of the percentage change in all the above mentioned neutral species is shown in Fig. 1 for the altitude region of $15-120 \mathrm{~km}$. The percentage change in NO and $\mathrm{O} 2$ decreases for the double $\mathrm{CO}_{2}$ scenario in the MLT region. The change in $\mathrm{NO}$ is positive $(18 \%$ at $30 \mathrm{~km})$ for the stratosphere, whereas it decreases monotonically in the mesosphere and becomes around $-40 \%$ and $-90 \%$ at $80 \mathrm{~km}$ and $110 \mathrm{~km}$, respectively. The concentration of water vapour increases for the double $\mathrm{CO}_{2}$ scenario in both stratosphere and MLT regions. The increase is around $10 \%$ in the stratosphere and lower mesosphere, and becomes around $20 \%$ in the lower thermospheric region. The percentage change in atomic oxygen is $-40 \%$ around $40 \mathrm{~km}$, which becomes positive $(20 \%$ at $90 \mathrm{~km})$ in the upper mesosphere and thermosphere. The percentage change in the concentration of acetonitrile is almost negligible in the lower stratosphere but increases by $30 \%$ at about $50 \mathrm{~km}$, which further increases in the lower mesosphere.

\section{Temperature perturbation in the MLT-region}

As evident from the recent literature (Beig et al., 2003), the long-term trend in the temperature indicates a cooling of the order of $3-4^{\circ} \mathrm{C}$ per decade in the mesosphere, which further increases in the upper mesosphere but becomes zero near the mesopause region. The trend again starts to show cooling in the lower thermosphere. In recent times, a few detailed model studies using an upper atmospheric general circulation model are reported (Schmidt et al., 2006; Garcia et al., 2007)

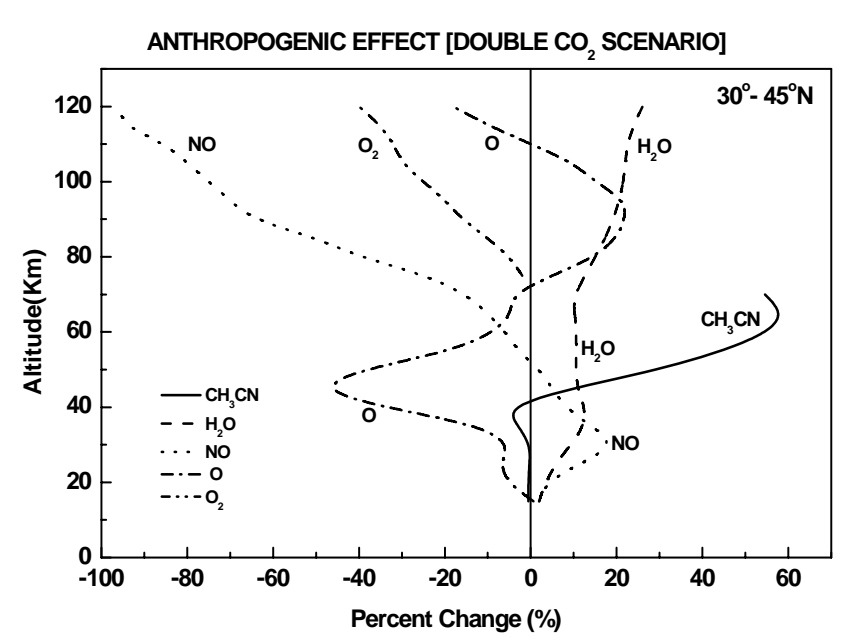

Fig. 1. Percentage change in the concentrations of various important neutral species for the double- $\mathrm{CO}_{2}$ scenario for the middle atmosphere for $30^{\circ}-45^{\circ} \mathrm{N}$ latitude.

which have nearly reproduced the no trend feature in temperature near the mesopause region. Schmidt et al. (2006) have used the three-dimensional Hamburg Model of the Neutral and Ionized Atmosphere (HAMMONIA), which treats atmospheric dynamics, radiation, and chemistry interactively for the height range from the Earth's surface to the thermosphere (approximately $250 \mathrm{~km}$ ). HAMMONIA represents a new generation of atmospheric models that try to combine classical general circulation models with comprehensive chemistry over a large altitude range. It is difficult to evaluate the model results for a doubling of $\mathrm{CO}_{2}$ with observational data. However, if one assumes that the temperature trends observed for the past decades in the middle and upper atmosphere are mainly due to the $\mathrm{CO}_{2}$ increase, the lack of a detectable trend in the summer mesopause region, as reported by Beig et al. (2003), is consistent with model results for a $\mathrm{CO}_{2}$ doubling. Garcia et al. (2007) used the Whole Atmosphere Community Climate Model to produce a small (three-member) ensemble of simulations of the period 1950-2003. They have reported that near the mesopause, at $80-90 \mathrm{~km}$, temperature trend is either insignificant or very small. The lack of a temperature trend in a range of altitude where $\mathrm{CO}_{2}$ is the main infrared emitter is puzzling, but consistent with observations (Beig, 2006). The temperature change, as obtained by the above-mentioned 2-D model for the stratosphere, is used in the ion chemical scheme. For the MLT-region, a 2-D model is unable to reproduce the no trend feature near the mesopause region and hence, the temperature change for the MLT-ion chemical scheme is taken from Schmidt et al. (2006) for the double $\mathrm{CO}_{2}$ scenario at the mid latitude. 


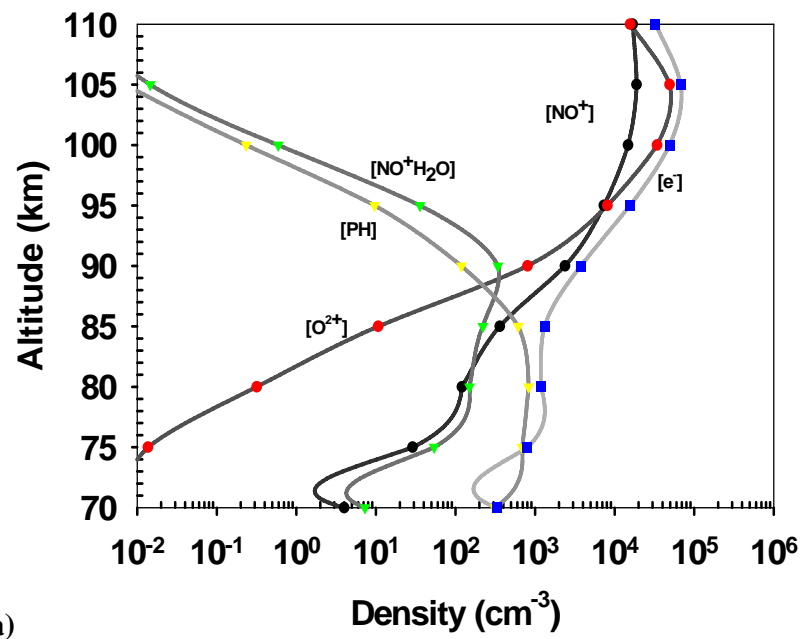

(a)

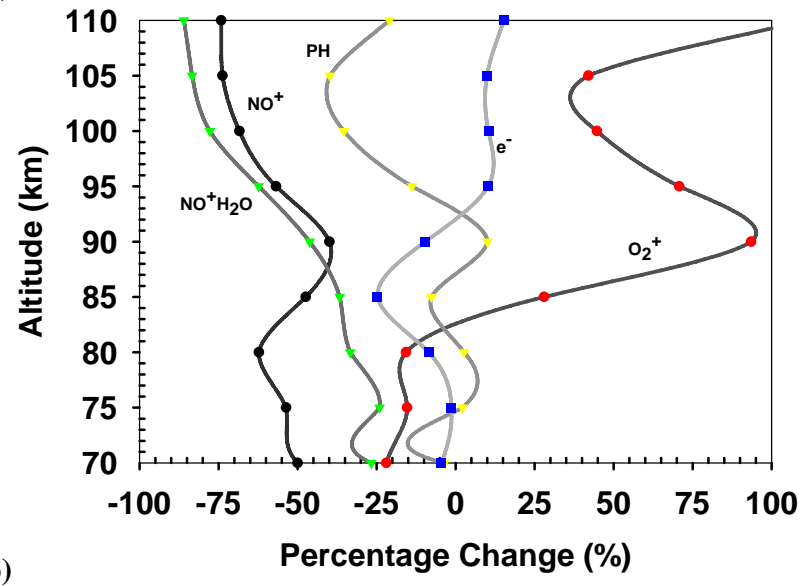

Fig. 2. (a) The number density (/cc) of major positive ions in the MLT region for background case; (b) Model results of percentage change in major positive ions for the double- $\mathrm{CO}_{2}$ scenario in the MLT region at $10^{\circ} \mathrm{N}$ latitude as obtained in this work.

\section{Perturbations in ion composition of the MLT-region}

Figure 2a shows the vertical distribution of the concentration of the major positive ions (/cc) in the MLT region for the normal background case. It can be noticed from Fig. 2a that the $\mathrm{PH}$ family of ions is the most dominant below $85 \mathrm{~km}$ followed by $\mathrm{NO}^{+}$and $\mathrm{NO}^{+}\left(\mathrm{H}_{2} \mathrm{O}\right)$. Above $85 \mathrm{~km}, \mathrm{NO}^{+}$and $\mathrm{O}_{2}^{+}$ions start to dominant. The total electron density in the MLT region varies from $10^{3} / \mathrm{cc}$ to $10^{5} / \mathrm{cc}$. Figure $2 \mathrm{~b}$ shows the vertical distribution of the percentage change in ion composition of the MLT-region, as obtained in the present work for the double $\mathrm{CO}_{2}$ scenario, compared to background case. The concentration of electron density does not change appreciably in the lower mesosphere but it starts to decrease above about $75 \mathrm{~km}$. The maximum negative trend is $25 \%$ at $85 \mathrm{~km}$, above which the magnitude of the negative trend decreases and becomes negligible at $93 \mathrm{~km}$. A positive trend of the order of $10-15 \%$ is simulated for the altitude range of
95-110 km. The concentration of almost all the major ions decreases in the lower mesosphere up to about $80 \mathrm{~km}$. The decrease in $\mathrm{NO}^{+}$and $\mathrm{NO}^{+}\left(\mathrm{H}_{2} \mathrm{O}\right)_{n}$ ions is substantial. The percentage change is found to be around $-50 \%$ to $-60 \%$ for $\mathrm{NO}^{+}$ions in the mesosphere. The magnitude of the negative trend decreases marginally near the mesopause region and then again starts to increase with height. The percentage change is $-50 \%$ to $-80 \%$ in the lower thermosphere for $\mathrm{NO}^{+}$and $\mathrm{NO}^{+}\left(\mathrm{H}_{2} \mathrm{O}\right)_{n}$ ions, respectively. The percentage change in proton hydrate ions increases marginally $(10 \%$ at $90 \mathrm{~km}$ ) near the mesopause region but it also becomes negative in the free thermosphere $(40 \%$ at $105 \mathrm{~km})$ for the double $\mathrm{CO}_{2}$ scenario. The only ion which undergo a drastic positive trend is $\mathrm{O}_{2}^{+}$above the mesopause region. The changes in $\mathrm{O}_{2}+$ are found to be $-25 \%$ in the lower mesosphere which becomes positive (maximum up to about $90 \%$ at $90 \mathrm{~km}$ ) in the lower thermosphere.

\section{Perturbations in ion composition of the stratosphere}

Figure 3a shows the vertical distribution of the concentration of the major positive ions (/cc) in the stratosphere for the normal background case for $45^{\circ} \mathrm{N}$. It can be noticed from this figure that the NPH family of ions is the most dominant below $35 \mathrm{~km}$, whereas the PH family of ions dominates above this altitude. The crossover altitude for this latitude region is around $35 \mathrm{~km}$, as also confirmed by observations. For the normal case, the aerosol cluster ions are always in the minority, as is evident from Fig. 3a. The total positive ion density in the stratosphere varies from $1-5 \times 10^{3} / \mathrm{cc}$. The percentage change in the major stratospheric positive ions, along with the total positive ion density and the NPH/PH ratio for the double- $\mathrm{CO}_{2}$ scenario at $45^{\circ} \mathrm{N}$ latitude, is shown in Fig. 3b. The marginal variation in water vapor (Fig. 1) is not sufficient to induce significant changes in the concentrations of the PH ion family. The concentration of the NPH ion family is mainly driven by the abundance of $\mathrm{CH}_{3} \mathrm{CN}$. The concentration of $\mathrm{CH}_{3} \mathrm{CN}$ either does not change or decreases marginally in the lower stratosphere but it increases sharply above $40 \mathrm{~km}$ for the double $\mathrm{CO}_{2}$ scenario, as shown in Fig. 1. As a result of this, the NPH ion trend decreases up to about $-8 \%$ at $38 \mathrm{~km}$, followed by a sharp increase of around $30 \%$ at the stratopause. The ratio of NPH/PH ions increases sharply above the $40-\mathrm{km}$ altitude, due to an increase in the NPH concentration. The percentage variation in this ratio is uniformly positive in the stratosphere. The aerosol cluster ions are not significant in the stratosphere under normal background conditions unless some volcanic eruption takes place. However, aerosol cluster ions show a positive trend that decreases with increasing altitude. The concentrations of these ions are almost negligible in this altitude range. It is clear from this figure that there is a variation in the break-up of ions, but total ion density (profile 4) does not 
show any significant change with a maximum variation of $-4 \%$ between 25 and $35 \mathrm{~km}$ altitudes.

\section{Tropospheric ion composition}

The first ion composition measurements near the ground reported by Eisele (1983) revealed the presence of unidentified positive ions with masses of 80 and 94 amu. Thereafter, a few more high-resolution mass spectrometric measurements of naturally occurring tropospheric ions have been performed (Tanner and Eisele, 1991). Beig and Brasseur (1999, 2000) have made the first attempt to model the positive ions in the troposphere which include detailed pyridinated cluster ions. Their scheme is still valid and considered to be the latest in this field. In absence of sufficient ion schemes for the troposphere, obviously work related to anthropogenic perturbations was sparse. The only work which is available is by Beig and Brasseur (1999). The major source of ionization in the troposphere is provided by the action of galactic cosmic rays and of radioactivity ( $\alpha, \beta$ and $\gamma$ radiation from thoron and radon) on air molecules. The chemical scheme proposed by Beig and Brasseur $(1999,2000)$ to describe the major ionic processes in the troposphere is summarized here. The first ions formed are $\mathrm{O}_{2}^{+}$and $\mathrm{N}_{2}^{+}$which are immediately (less than $10^{-3} \mathrm{~s}$ ) converted to proton hydrates $\mathrm{H}^{+}\left(\mathrm{H}_{2} \mathrm{O}\right)_{n}$ after several intermediate steps (Ferguson et al., 1979). One or more water molecules included in these clusters can be substituted by other molecules with a high proton affinity. As suggested by Eisele $(1986,1988)$, stable "pyridinated cluster ions" of the form $\mathrm{H}^{+}\left(\mathrm{NH}_{3}\right)_{n}(\mathrm{X})_{m}\left(\mathrm{H}_{2} \mathrm{O}\right)_{l}$ (where $\mathrm{X}$ represents either pyridine, picoline, or lutidine, and $1, \mathrm{~m}, \mathrm{n}$ may be equal to or greater than zero) are formed. Their scheme also shows the formation of other non-proton hydrates (acetone cluster ions $\left[\mathrm{H}^{+}\left(\mathrm{CH}_{3} \mathrm{COCH}_{3}\right)\left(\mathrm{H}_{2} \mathrm{O}\right)_{n}\right]$, methyl cyanide cluster ions $\left.\left[\mathrm{H}^{+}\left(\mathrm{CH}_{3} \mathrm{CN}\right)\left(\mathrm{H}_{2} \mathrm{O}\right)_{n}\right]\right)$, and of aerosol cluster ions $\left[\mathrm{H}^{+}\right.$(Aerosol) $\left.(\mathrm{Y})_{p}\left(\mathrm{H}_{2} \mathrm{O}\right)_{n}\right]$, where $\mathrm{Y}$ represents one of the parent neutral species. The reaction rates adopted by them are listed in Beig and Brasseur (2000). The tropospheric ion pair production rate, and the concentration of aerosols (nonvolcanic conditions) are based on the work of Rosen et al. (1985) and the value adopted for the effective attachment coefficient of an ion on aerosols $\left(\beta=5 \times 10^{-6} \mathrm{~cm}^{3} \mathrm{~s}^{-1}\right)$ is taken from Datta et al. (1987). The recombination rate for positive/negative ions is adopted from the study of Arijs and Brasseur (1986).

\section{Anthropogenic perturbations in tropospheric ion composition}

The chemistry of the neutral species (especially the pyridinated compounds) that take part in ion chemistry and their proton exchange process are not yet properly known. It is believed that combustion is a major source for these compounds, and hence their atmospheric abundance is expected
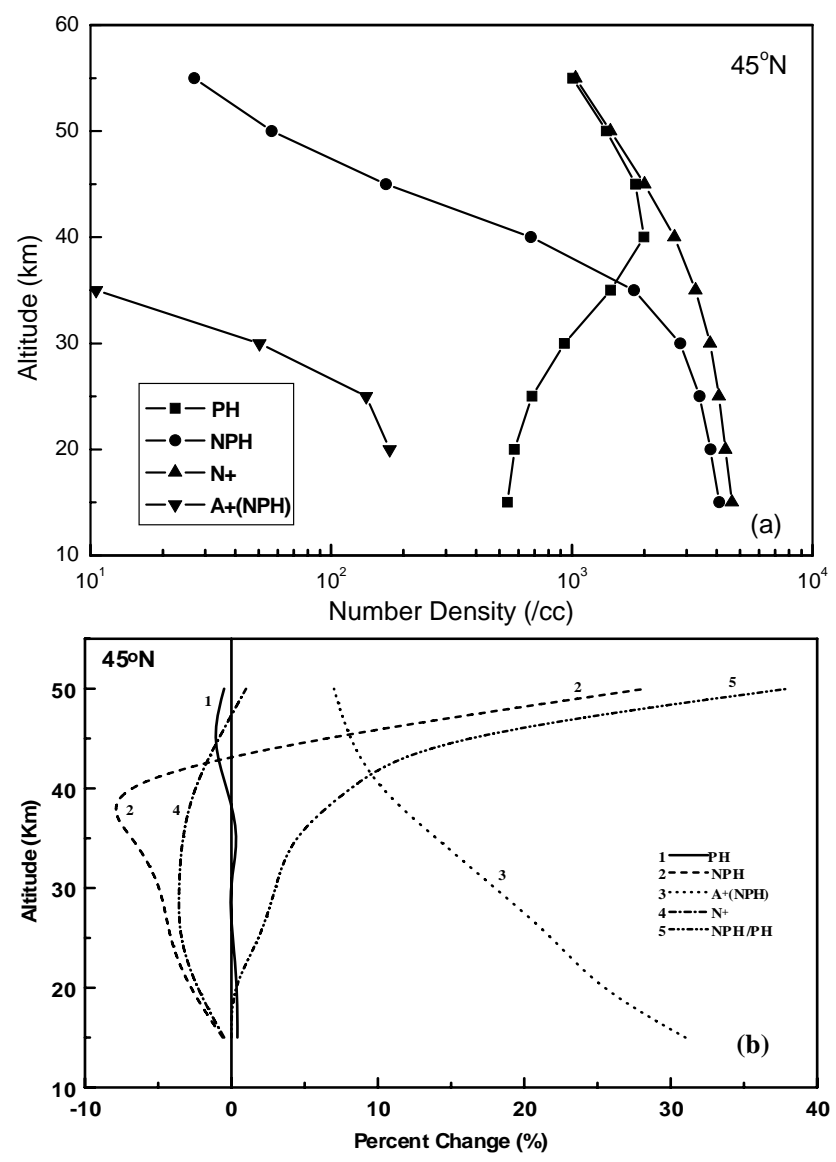

Fig. 3. (a) The number density (/cc) of major positive ions in the stratosphere for background case; (b) Model results of percentage change in major stratospheric positive ions for the double- $\mathrm{CO}_{2}$ scenario at $45^{\circ} \mathrm{N}$ latitude as obtained in this work.

to be increasing substantially as a result of human activities. For example, methyl cyanide is known to be released in the atmosphere as a result of biomass burning, and has been observed in automobile exhaust gases and tobacco smoke (Hamm and Warneck, 1990). In addition to its emission by vegetation and biomass burning, acetone is produced mainly from the oxidation of anthropogenic hydrocarbons (Singh et al., 1994). The sources of pyridinated compounds are believed to be primarily automobile exhaust, biomass burning, manufacturing and agricultural use, coal tars and tobacco smoke (Graedel, 1978). Emission by the ocean could be an additional, but probably small atmospheric source. The atmospheric abundance of these parent neutral compounds, and hence the ionic composition of the troposphere has most probably changed over the last decades as a result of human activities, and is expected to change further in the future. The magnitude of these changes cannot be properly established due to the lack of systematic observations of these compounds and the uncertainties associated with their sources 


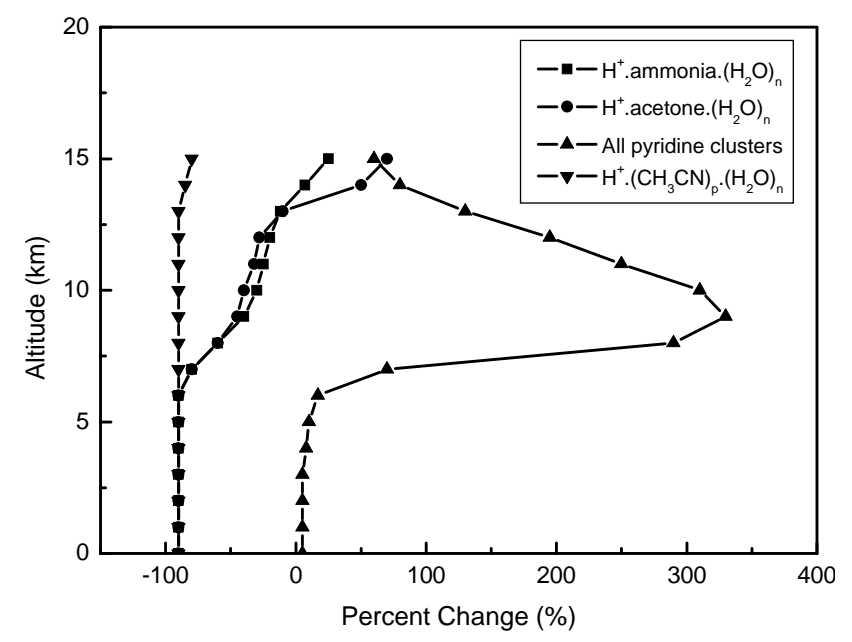

Fig. 4. Percentage change in major tropospheric positive ion composition for the scenario where concentration of all neutral compounds is increased by an arbitrary factor 10 from the background case.

and sinks. In order to determine the potential response of the ionic composition of the troposphere to human activities, Beig and Brasseur (1999) have considered a scenario where the concentration of all compounds is increased by an arbitrary factor 10 from the background case. We have also considered the same scenario. The percentage changes in the ion concentration with respect to the background case are shown in Fig. 4 for this scenario. As evident, the largest positive change $(350 \%$ at $8 \mathrm{~km})$ is found for the pyridinated ions in the upper troposphere. Changes in the abundance of these ions are, however, small below $5 \mathrm{~km}$. The concentration of the other ions is reduced by a factor 2 below $5 \mathrm{~km}$ altitude (and up to $15 \mathrm{~km}$ in the case of methyl cyanide cluster ions).

\section{Conclusions}

Global change effects in the ion composition of the lower and upper atmosphere were given the least attention so far. Some of the recent studies do, however, confirm the few available observations in these regions. It is found that ionic compositions undergo significant variations. The variations calculated for the double- $\mathrm{CO}_{2}$ scenario are both long-term and permanent in nature. It is shown that a decrease in NO number density up to $-80 \%$ for the double- $\mathrm{CO}_{2}$ scenario in the mesosphere is one of the major reasons for the modeled variations in ionized parameters for this region. In addition, cooling up to about $-14^{\circ} \mathrm{K}$ (2-D model), a decrease in the acetonitrile number density $(-10 \%$ at $40 \mathrm{~km})$, and an increase in water vapor by $5-15 \%$ in the stratosphere are major factors that were found to cause variations in stratospheric charged species for the double- $\mathrm{CO}_{2}$ scenario. The no trend feature in temperature around the mesopause region with a negative trend below and above this altitude region for the double $\mathrm{CO}_{2}$ scenario has a substantial impact in the variation of total electron density and ion composition as compared to results reported by earlier workers. The concentration of electron density does not change appreciably in the lower mesosphere but it starts to decrease above about $75 \mathrm{~km}$ until about $85 \mathrm{~km}$, above which the magnitude of the negative trend decreases and becomes negligible at $93 \mathrm{~km}$. A positive trend of the order of $10-15 \%$ is simulated for the altitude range of $95-110 \mathrm{~km}$. The concentration of almost all the major ions decreases in the lower mesosphere up to about $80 \mathrm{~km}$. The percentage change is $-50 \%$ to $-80 \%$ in the lower thermosphere for $\mathrm{NO}^{+}$and $\mathrm{NO}^{+}\left(\mathrm{H}_{2} \mathrm{O}\right)_{n}$ ions, respectively. The only ion which undergo a drastic positive trend is $\mathrm{O}_{2}^{+}$above the mesopause region. In the stratosphere, the NPH/PH ratio increases slowly in the lower stratosphere and quite substantially in the upper stratosphere.

In the troposphere, it is suggests that, in moderately or strongly polluted environments, pyridinated cluster ions are the most abundant ions below $7 \mathrm{~km}$. The percentage growth of these ions is very high for the entire troposphere, especially above $7 \mathrm{~km}$. In the upper troposphere, the dominant ions appear to be acetone clusters. The ion composition of the troposphere is expected to change in the future in response to human activities, resulting in enhanced emissions of anthropogenic compounds, including pyridine, picoline and lutidine. Model calculations suggest that the atmospheric density of pyridinated cluster ions is rising rapidly.

Acknowledgements. Topical Editor U.-P. Hoppe thanks J. Bremer and A. Viggiano for their help in evaluating this paper.

\section{References}

Akmaev, R. A. and Fomichev, V. I.: Cooling of the mesosphere and lower thermosphere due to doubling of $\mathrm{CO}_{2}$, Ann. Geophys., 16, 1501-1512, 1998, http://www.ann-geophys.net/16/1501/1998/.

Arijs, E. and Brasseur, G.: Acetonitrile in the stratosphere and implications for positive ion composition, J. Geophys. Res., 91, 4003-4016, 1986.

Beig, G.: The Relative Importance of Solar Activity and Anthropogenic Influences on the Ion Composition, Temperature and Associated Neutrals of the Middle Atmosphere, J. Geophys. Res., 105, 19841-19856, 2000.

Beig, G.: Trends in the mesopause region temperature and our present understanding - an update, Phys. Chem. Earth, 31, 3-9, doi:10.1016/j.pce.2005.03.007, 2006.

Beig, G. and Brasseur, G.: Anthropogenic perturbations of tropospheric ions, Geophys. Res. Lett., 26, 1303-1306, 1999.

Beig, G. and Brasseur, G.: Model of Tropospheric Ion Composition: A First Attempt, J. Geophys. Res., 105, 22 671-22 684, 2000.

Beig, G. and Mitra, A. P.: Atmospheric and ionospheric response to trace gas perturbations through the ice age to the next century in the middle atmosphere, part I - Chemical composition and thermal structure, J. Atmos. Sol. Terr. Phys., 59, 1245-1259, 1997a. 
Beig, G. and Mitra, A. P.: Atmospheric and ionospheric response to trace gas perturbations through the ice age to the next century in the middle atmosphere, part II - Ionization, J. Atmos. Sol. Terr. Phys., 59, 1261-1275, 1997b.

Beig, G., Walters, S., and Brasseur, G.: A two-dimensional model of ion composition in the stratosphere, 1, Positive ions, J. Geophys. Res., 98, 12 767-12 773, 1993.

Beig, G., Keckhut, P., Lowe, R. P., Roble, R., Mlynczak, M. G., Scheer, J., Fomichev, V., Offermann, D., French, W. J. R., Shepherd, M. G., Semenov, A. I., Remsberg, E. E., She, C. Y., Lübken, F. J., Bremer, J., Clemesha, B. R., Stegman, J., Sigernes, F., and Fadnavis, S.: Review of Mesospheric Temperature Trends, Rev. Geophys., 41(4), 1-1-1-41, 1015, doi:10.1029/2002RG000121, 2003.

Berger, U. and Dameris, M.: Cooling of the upper atmosphere due to $\mathrm{CO}_{2}$ increases: "A model study", Ann. Geophys., 11, 809819,1993 , http://www.ann-geophys.net/11/809/1993/.

Chakrabarty, D. K.: On long-term changes of electron density in the upper mesosphere, Adv. Space Res., 35(8), 1411-1415, 2005.

Chakrabarty, D. K., Chakrabarty, P., and Witt, G.: J. Atmos. Terr. Phys., 40, 437-443, 1978.

Curtis, A. R. and Goody, R. M.: Thermal radiation in the upper atmosphere, Proc. R. Soc. London, Ser. A, 236, 193-206, 1956.

Danilov, A. D.: Long-term changes of the mesosphere and lower thermosphere temperature and composition, Adv. Space Res., 20, 2137-2147, 1997.

Danilov, A. D. and Smirnova, N. V.: Long-term trends of the ion composition in the E-region, Geomagn. Aeron., 37, 35-46, 1997.

Datta, J., Revankar, C. P., Chakravarty, S. C., and Mitra, A. P.: Influence of aerosols on middle atmospheric conductivities, Phys. Scr., 36, 705-710, 1987.

Eisele, F. L.: Direct tropospheric ion sampling and mass identification, Int. J. Mass Spectrom. Ion Phys., 54, 119-126, 1983.

Eisele, F. L.: Identification of tropospheric ions, J. Geophys. Res., 91, 7897-7906, 1986.

Eisele, F. L.: First tandem mass spectrometric measurement of tropospheric ions, J. Geophys. Res., 93, 716-724, 1988.

Ferguson, E. E., Fehsenfeld, F. C., and Albritton, D. L.: Ion chemistry of the Earth's atmosphere, in: Gas Phase Ion Chemistry, edited by: Bowers, M. T., vol. 1, pp. 45-82, Academic Press, New York, 1979.
Garcia, R. R., Marsh, D. R., Kinnison, D. E., Boville, B. A., and Sassi, F.: Simulation of secular trends in the middle atmosphere, 1950-2003, J. Geophys. Res., 112, D09301, doi:10.1029/2006JD07485, 2007.

Graedel, T. E.: Chemical Compounds in the Atmosphere, Academic, Orlando, Fla., 1978.

Hamm, S. and Warneck, P.: The interhemispheric distribution and the budget of acetonitrile in the troposphere, J. Geophys. Res., 95, 20 593-20 606, 1990.

Ramaswamy, V., Chanin, M. L., Angell, J., Barnett, J., et al.: Stratospheric temperature trends: Observations and model simulations, Rev. Geophys., 39, 71-122, 2001.

Rishbeth, H.: Long-term changes in the ionosphere, Adv. Space. Res., 20, 2149-2155, 1997.

Rishbeth, H. and Roble, R. G.: Cooling of the upper atmosphere by enhanced greenhouse gases: Modelling of thermospheric and ionospheric effects, Planet. Space Sci., 40, 1011-1026, 1992.

Roble, R. G. and Dickinson, R. E.: How will changes in carbon dioxide and methane modify the mean structure of the mesosphere and thermosphere?, Geophys. Res. Lett., 16, 1441-1444, 1989.

Rosen, J. M., Hofmann, D. J., and Gringel, W.: Measurements of ion mobility to $30 \mathrm{~km}$, J. Geophys. Res., 90, 5876-5884, 1985.

Schmidt, H., Brasseur, G. P., Charron, M., Manzini, E., et al.: The HAMMONIA Chemistry Climate Model: Sensitivity of the Mesopause region to the 11-Year Solar Cycle and $\mathrm{CO}_{2}$ Doubling, J. Climate, 19, 3903-3931, 2006.

Singh, H. B., O’Hara, D., Herlth, D., Sachse, W., Blake, D. R., Bradshaw, J. D., Kanakidou, M., and Crutzen, P. J.: Acetone in the atmosphere: Distribution, sources and sinks, J. Geophys. Res., 99, 1805-1819, 1994.

Tanner, D. J. and Eisele, F. L.: Ions in oceanic and continental air mass, J. Geophys. Res., 96, 1023-1031, 1991.

Thomas, G. E.: Global change in thermosphere-lower thermosphere region : Has it already arrived?, J. Atmos. Terr. Phys., 58, 16291656, 1996.

WMO: Scientific Assessment of Ozone Depletion: 1998, Rep. 44, Global Ozone Res. and Monit. Proj., Geneva, 1999. 